\title{
Pelatihan Tari untuk Remaja Putri Reog Kaloka di Suru, Kemadang, Tanjungsari,
Gunungkidul
}

\author{
Hendro Martono \\ Jurusan Tari, Fakultas Seni Pertunjukan \\ Institut Seni Indonesia Yogyakarta \\ Jalan Parangtritis Km 6,5, Sewon, Bantul, Daerah Istimewa Yogyakarta 55188 \\ No. Hp.: +628121560610, E-mail: hendromartono401@gmail.com
}




\title{
Pelatihan Tari untuk Remaja Putri Reog Kaloka di Suru, Kemadang, Tanjungsari, Gunungkidul
}

\author{
Hendro Martono \\ Jurusan Tari, Fakultas Seni Pertunjukan \\ Institut Seni Indonesia Yogyakarta \\ Jalan Parangtritis Km 6,5, Sewon, Bantul, Daerah Istimewa Yogyakarta 55188 \\ No.Hp.: +628121560610, E-mail: hendromartono401@gmail.com
}

\begin{abstract}
Abstrak
Reog Kaloka merupakan sebuah kelompok seni (paguyuban) rakyat dari Suru, Kemadang, Gunungkidul, Daerah Istimewa Yogyakarta yang sangat populer dengan tari Reognya di Gunungkidul pada era 2010-2014. Setelah paguyuban ini mempelajari tari kreasi baru yang berasal dari Sleman, yakni tari Gedruk yang energik; tari Reog menjadi tersingkirkan. Hanya tinggal anakanak kecil yang berminat menarikannya, itu pun terbatas dalam acara tertentu seperti bersih desa. Hal ini sangat disayangkan, hingga timbullah inisiasi mengadakan penyuluhan ini. Penyuluhan ini bertujuan untuk melatih teknik gerak tari gaya Yogyakarta agar para peserta menguasai gerak alusan seperti halnya dalam tari Reog. Diharapkan, belajar tari dasar ini akan memberikan fondasi yang kuat khususnya kepada penari perempuan, mengingat Reog lebih dominan dibawakan oleh perempuan sebagaimana Reog Kaloka dulu pada masa jayanya. Penyuluhan ini dilaksanakan pada 23 Maret hingga 27 April 2021. Metode yang diterapkan meliputi pelatihan praktik tari dengan penjelasan awal yang singkat, kemudian demonstrasi, dilanjutkan dengan peserta mengikuti gerak yang dilakukan oleh pelatih secara langsung terutama gerak tangan, kepala, dan kaki secara parsial. Tahap selanjutnya, peserta mengikuti gerakan pelatih saat menari secara keseluruhan dengan hitungan, kemudian diteruskan dengan musik tarinya. Hasil yang didapatkan adalah kemampuan anak dan remaja putri dalam menari Jawa gaya Yogyakarta meskipun belum dalam taraf sempurna; dengan pementasan tari Nawung Sekar di Pendhapa Pantai Kukup, Gunungkidul.
\end{abstract}

Kata kunci: Reog Kaloka, tari Jawa, Nawung Sekar, Gunungkidul

\section{Reog Kaloka Dance Training for Teenage Girls in Suru Kemadang Tanjungsari Gunungkidul}

\footnotetext{
Abstract

Reog Kaloka is a communal dance group in Suru, Kemadang, Gunungkidul, Special Region of Yogyakarta whose Reog dance was very popular in Gunungkidul during 2010-2014. The dance group then learned and practiced new dance creation originated from Sleman, which is the energetic Gedruk dance; this leads to Reog dance being left out. Only children are still on interest in dancing them and it was limited to those in bersih desa. It was highly unfortunate thus becomes the objective of this training initiation. This training is aimed to practice Yogyakarta dance style technique so that the participants can master alusan (smooth) movement like those in Reog dance. It is hoped that the basic dance technique learning can give a better foundation on female dancers, as Reog is more dominantly performed by women just like Reog Kaloka once in its glory. The training is held at 23 to 27 March 2021. The method used covers dance practice from oral brief explanation, dance demonstration, continued with the participants directly following the movement done by the trainers, especially in hand, head, and feet movement partially. Next step, the participants follow the trainers' movement when they dance in full motion with rhythm tempo, then followed with music accompaniment. The results gained is the achieved skill of teenage girls in Java dancing Yogyakarta style although it has not reached the perfect stage yet; with the stage performance of Nawung Sekar dance in Pendhapa Pantai Kukup, Gunungkidul.

Keywords: Reog Kaloka, Java dance, Nawung Sekar, Gunungkidul
} 


\section{PENDAHULUAN}

Dusun Suru, Kemadang, Tanjungsari, Gunung Kidul memiliki sebuah kelompok seni reog yang menjadi kebanggaan masyarakat setempat, yakni Paguyuban Seni Reog Kreasi Kaloka. Reog tersebut sedang berproses mengembangkan diri dengan semangat yang sangat tinggi yang dimulai pada 15 Juni 1999. Reog Kaloka beranggotakan sekitar 40 orang, lengkap dengan pengrawitnya. Eksistensinya termotivasi oleh program Pemerintah Desa Kemadang, yakni meningkatkan kualitas desa penyangga wisata Pantai Baron dan Kukup guna menaikkan Pendapatan Asli Daerah (PAD) (wawancara dengan Kepala Desa Kemadang, 28 Oktober 2000). Reog Kaloka dibentuk oleh pemuda-pemuda yang mempunyai latar belakang kesenian karawitan dan ketoprak, yang prihatin melihat nasib reog tradisionalnya yang semakin dijauhi oleh pendukungnya. Berdasarkan hal ini, didirikanlah paguyuban seni Reog kreasi "Kaloka" yang mengemban misi nguri-nguri budaya leluhur dan juga mengembangkan kesenian tradisional menjadi kreasi baru yang menghibur sehingga dapat diterima kembali oleh masyarakatnya (wawancara dengan pelatih, Suparno dan Sugiyo, Ketua Paguyuban, Oktober 2000).

Reog Kaloka mencapai kejayaan pada tahun 2000-2014 yang ditandai dengan didapatkannya berbagai pelatihan dan bantuan peralatan melalui para peneliti. Bantuan ini antara lain datang dari penulis selaku dosen penyuluh seni melalui berbagai skema penelitian sejak tahun 2000 hingga 2011. Penulis berhasil mendapatkan bantuan dana ipteks sebanyak dua kali, Beasiswa Unggulan sebanyak dua kali, program P3Wilsen pada tahun 2009, dan karya seni yang berbasis pengabdian kepada masyarakat pada tahun 2006. Pada tahun
2011, pengusul pun menggunakan tari Reog sebagai karya seni studi S-3 Penciptaan Seni.

Keadaan mulai berubah ketika pada tahun 2014 paguyuban ini menekuni pula tari Gedruk, dengan tujuan mulia untuk memperkaya materi tari Reog Kaloka. Pada saat itu didatangkanlah pelatih tari Gedruk lengkap dengan 12 topeng dan kerincing kaki yang menjadi ciri utama kesenian asal Sleman itu. Akan tetapi, upaya ini ibarat menjadi senjata makan tuan. Seiring perjalanan waktu, para penari reog laki-laki yang juga menekuni Gedruk tidak mau lagi berlatih atau menarikan Reog. Imbasnya, mati surilah Reog ini selama sekitar lima tahun. Akhirnya, Reog pun terpinggirkan dan hanya dipentaskan dalam acara bersih desa dengan penari anakanak yang belum memahami teknik gerak, apalagi soal olah rasa. Rasa merupakan faktor penting yang harus melekat pada diri seorang penari. Sulastuti mendefinisikan "rasa" sebagai berikut.

"Rasa, dimaksudkan sebagai suatu kondisi psikis tari sekaligus penarinya. Rasa juga diartikan sebagai respons psikis / batin individu-penonton/penghayat setelah menikmati sebuah karya tari. Sebagai respons psikis dari stimulan bentuk tari, rasa ditangkap melalui indra fisik dan nonfisik" (Sulastuti, 2013:42).

Melihat kondisi yang sedemikian rupa, penulis merasa bersalah dan bertekad berupaya membangkitkan kembali gairah berkesenian Reog yang dulu sangat terkenal di Gunungkidul. Melalui penyuluhan seni yang dibantu oleh satu orang mahasiswi sebagai pelatih tari putri ini diharapkan langkah awal membenahi kembali Reog dapat terlaksana.

Apa yang dialami oleh Reog Kaloka sekarang ini sungguh tragis, mengalami mati suri akibat dari bumerang melatih tari Gedruk yang sangat disenangi baik oleh 
penari Reog maupun masyarakat penonton. Untuk itu, perlu diadakan penyuluhan kembali yang dalam hal ini bermaksud memberikan pelatihan tari kreasi Nawungsekar. Tari Nawungsekar ini berangkat dari tradisi yang berbeda dari tari gedruk sehingga diharapkan dapat mendukung teknis gerak serta semangat menari dengan karakter yang lembut seperti halnya reog.

Solusinya, Reog Kaloka ini harus dibangun kembali dari awal serta menumbuhkan sikap berkesenian bagi generasi penerus Reog, bahwa Reog merupakan warna lokal Gunungkidul yang harus dipertahankan dan dikembangkan sesuai kemauan zaman. Rencana kegiatan berupa pelatihan tari bagi generasi penerus baik anggota reog maupun yang bukan anggota. Tari yang diajarkan adalah tari Nawungsekar, yaitu tari dasar yang sederhana dengan gaya Yogyakarta. Diharapkan dalam 12 kali pertemuan atau latihan warga Reog Kaloka bisa menarikan dengan hafal walaupun belum menguasai roh tari Yogyakarta yang halus. Rencana tersebut merupakan tahap awal yang akan berlanjut hingga Reog Kaloka kembali bangkit. Pelatihnya adalah mahasiswi Program Studi Seni Tari, FSP, ISI Yogyakarta. Melatih teknik gerak tari gaya Yogyakarta agar menguasai gerak alusan seperti gaya tari Reog sangat berbeda dengan tari Gedruk yang energik.

"Hadirnya kesenian rakyat di tengahtengah kehidupan masyarakat, tidak hanya semata-mata sebagai seni pertunjukan yang dapat dinikmati secara estetika (keindahan) dan untuk kesenangan semata, melainkan membawa fungsi yang dapat menjadi pedoman bagi masyarakat dalam menjalani kehidupan di tengah-tengah kehidupan sosio-kultural” (Isnanda \& Azkiya, 2019:216).
Diharapkan belajar tari dasar ini akan memberikan fondasi yang kuat kepada penari perempuan khususnya, sebab reog lebih dominan dibawakan oleh wanita, seperti halnya Reog Kaloka dulu. Target jangka panjang yang diharapkan adalah mengembalikan kejayaan Reog Kaloka yang merupakan salah satu ikon seni rakyat Gunungkidul. Target jangka pendek adalah melatih teknik gerak para generasi muda anggota paguyuban Reog Kaloka yang merupakan anak atau cucu pemain lama yang sudah tidak kuat lagi menari reog karena sudah uzur ataupun kesibukan kerja.

Kegiatan ini memiliki sejumlah manfaat. Bagi dosen, untuk pertanggungjawaban moral sebagai penyuluh, karena terlibat sejak tahun 2000 dalam mengembangkan Reog Kaloka. Terjadi bumerang pada tahun 2014 karena dosen melatih tari Topeng Grasak atau Gedruk dari Sleman yang berdampak pada kematian tari Reog yang sebenarnya menjadi ciri utama kelompok Reog Kaloka. Bagi Paguyuban Kaloka pelatihan ini sangat berarti untuk awal kebangkitan kembali setelah lima tahun mati suri karena penarinya lebih senang menarikan Gedruk daripada Reog. Bagi Pemerintah Dusun Suru dan Kemadang diuntungkan karena selama ini Reog Kaloka banyak membantu promosi potensi seni lokal yang cukup membanggakan. Reog Kaloka dulu sangat terkenal di daerah Gunungkidul karena paling inovatif dan kreatif, yang didukung oleh kekuatan banyak pemain.

\section{METODE PENGABDIAN}

Menggunakan metode pelatihan praktik tari, dengan penjelasan awal yang singkat, kemudian demonstrasi, dilanjutkan dengan peserta mengikuti gerak yang dilakukan oleh pelatih secara langsung terutama gerak tangan, kepala, dan kaki secara parsial. Tahap 
selanjutnya mengikuti gerakan pelatih saat menari secara keseluruhan dengan hitungan, kemudian diteruskan dengan musik tarinya. Terkadang pelatih harus memegang dan membetulkan posisi jari, tangan, kepala, dan bahu peserta. Metode pelatihan yang demikian ini sangat umum dilakukan oleh pelatih di mana pun di Nusantara.

\section{HASIL DAN PEMBAHASAN}

Khalayak sasaran adalah para generasi muda khususnya remaja putri, baik yang merupakan anggota Reog maupun yang bukan. Menurut Ifdil, Denich, \& Ilyas, remaja awal berada pada kisaran usia 10 sampai dengan 13 tahun; remaja akhir berada pada kisaran usia 18 sampai dengan 22 tahun (Ifdil et.al, 2017:107). Kebanyakan warga Dusun Suru, termasuk anak cucunya adalah anggota Reog. Wanita lebih dominan dalam tari Reog Gunungkidul. Maka dari itu penyuluhan ini difokuskan pada anakanak dan remaja putri. Dengan demikian, diharapkan nantinya yang menggerakkan kesenian di Desa Kemadang adalah kaum wanita. Hal itu sudah dimulai dengan adanya warga desa yang menjadi mahasiswa Program Studi Pendidikan Tari, Fakultas Bahasa dan Seni yang merupakan warga Kemadang Kulon. Selain itu, ada dua orang lagi yang juga wanita dari Kemadang Kulon dan Suru yang masih menempuh studi di Jurusan Tari di SMKI Yogyakarta. Artinya sudah tersimpan potensi daerah yang akan mengembangkan kesenian pada masa mendatang.

Kegiatan latihan bertempat di rumah Sugiyo di Pedukuhan Suru yang cukup luas dan berada di dalam rumah. Jadi, peserta tidak kepanasan. Sebetulnya, bisa saja bertempat di Balai Dusun Suru, tetapi setiap kali latihan peserta harus memindahkan kursi-kursi kayu yang cukup berat dan banyak agar ada ruang untuk latihan. Istri Sugiyo, yakni Sutinem dapat menyiapkan konsumsi sederhana dari dapur rumahnya tanpa harus mengantar ke lokasi balai dusun. Peralatan suara untuk flashdisk juga sudah tersedia di sana sehingga peserta tidak perlu direpotkan dengan angkat jinjing memindahkan peralatan ke tempat lain setiap kali latihan sebagaimana di balai dusun. Di rumah Pak Sugiyo juga tersedia kostum tari untuk praktik pentasny.

Pelatihan terdiri atas enam kali pertemuan dengan durasi latihan sekitar 3-4 jam tergantung dari kondisi anak-anak yang dilatih. Durasi demikian ini dihitung sebagai dua kali datang dikarenakan jarak lokasi Kemadang Gunungkidul dari Yogyakarta sekitar dua jam perjalanan yang melewati perbukitan kapur yang berkelok dan naik turun. Pelaksana penyuluhan mengajak satu mahasiswi dari Program Studi Tari semester VI, bernama Awanda Cahaya Buana. Pelatihan diadakan setiap Sabtu pukul 13.00-16.00 WIB.

Tabel 1 Daftar Peserta

\begin{tabular}{llll}
\hline No. & Nama & Status & Alamat \\
\hline 1. & Debora Kriswandari & Pelajar SMKI Yogyakarta & Suru \\
\hline 2 & Variska Selly A. & Pelajar SMAN Tanjungsari & Suru \\
\hline 3. & Novitasari & Pelajar SMPN Tanjungsari & Suru \\
\hline 4. & Y. Juvita Anggraini & Pelajar SMPN Mulo & Suru \\
\hline 5. & Dina Alin & Pelajar SMPN Tanjungsari & Suru \\
\hline 6. & Dea Love Renzi & Pelajar SMPN Tanjungsari & Kemadang Kulon \\
\hline
\end{tabular}




\begin{tabular}{llll}
\hline 7. & Amira Nur Asmi & SDN Kemadang & Suru \\
\hline 8. & Oktiola Giovanny & SDN Kemadang & Watu Belah \\
\hline 9. & Apri Dilla Wanda S. & SDN Kemadang & Watu Belah \\
\hline
\end{tabular}

Ada beberapa anak yang datang latihan sekali dua kali lalu tidak melanjutkan hingga akhir program. Peserta latihan dari Suru yang bernama Juvita adalah seorang penari Reog Kaloka dari Karang Lor. Ia juga penari Reog untuk dusunnya. Peserta yang masih menempuh pendidikan di sekolah dasar sama sekali belum pernah mengikuti latihan tari dan Reog. Mereka mengikuti program ini semata-mata hanya karena faktor kesenangan.

Materi tari yang dilatihkan adalah tari Nawung Sekar dari Yayasan Pemulangan Among Beksa yang juga menjadi materi tari dasar gaya Yogyakarta bagi anak-anak wanita di sanggar tersebut. Motif tari Nawung Sekar terdiri atas lampah sekar, duduk timpuh sembahan, kicat dengan coklekan kepala kanan kiri, kengser kanan kiri, serta srisik berputar kanan dan kiri juga. Motif tari tersebut memang merupakan motif dasar semua tari wanita gaya Yogyakarta yang mudah dilakukan oleh anak-anak. Ini memang belum ke gerak seperti nggurdha, encot, dan gerakan lainnya yang sulit. Gerakan yang sulit tersebut biasanya terdapat di tari Golek, Bedhaya, dan Srimpi yang merupakan materi untuk orang dewasa. Durasi tari Nawung Sekar sekitar lima menit. Menurut Kismini, tari Jawa klasik membutuhkan waktu yang tidak sedikit untuk diajarkan kepada para siswa (Kismini, 2013:117). Oleh karenanya, sangat wajar bila hasil pelatihan yang amat singkat ini masih belum sempurna. Berikut ini penjabaran lebih terperinci agenda pelatihan ini.

a. Pertemuan ke-1: 23 Maret 2019, pukul 13.00 - $16.00 \mathrm{WIB}$

1) Mendata peserta pelatihan yang terdiri dari sembilan anak dan remaja putri dari Suru, Karang Lor dan Watu Belah, Kelurahan Kemadang.

2) Menjelaskan singkat sambil memberi contoh posisi tangan ngithing atau ngolong dan nyempurit disertai gerak tangan ukel.

3) Latihan lengkap satu tarian Nawung Sekar dengan musik tari gamelan dari flashdisk. Peserta masih kesulitan karena mereka baru berlatih tari serius saat ada pelatihan ini saja. Kecuali anak Sugiyo yang bernama Debora Wanda. Ia sudah sangat menguasai tari dasar Yogyakarta karena bersekolah di Sekolah Menengah Kejuruan Negeri 1 Bantul atau SMKI Jurusan Tari. Ia juga penari Reog dan Gedruk atau Buto Grasak dari Suru. Terdapat dua anak yang dulu pernah menari Reog Kaloka, yakni Selly dan Novi, yang dalam hal teknik memang belum baik, tetapi dalam urutan tari cepat hafal. 


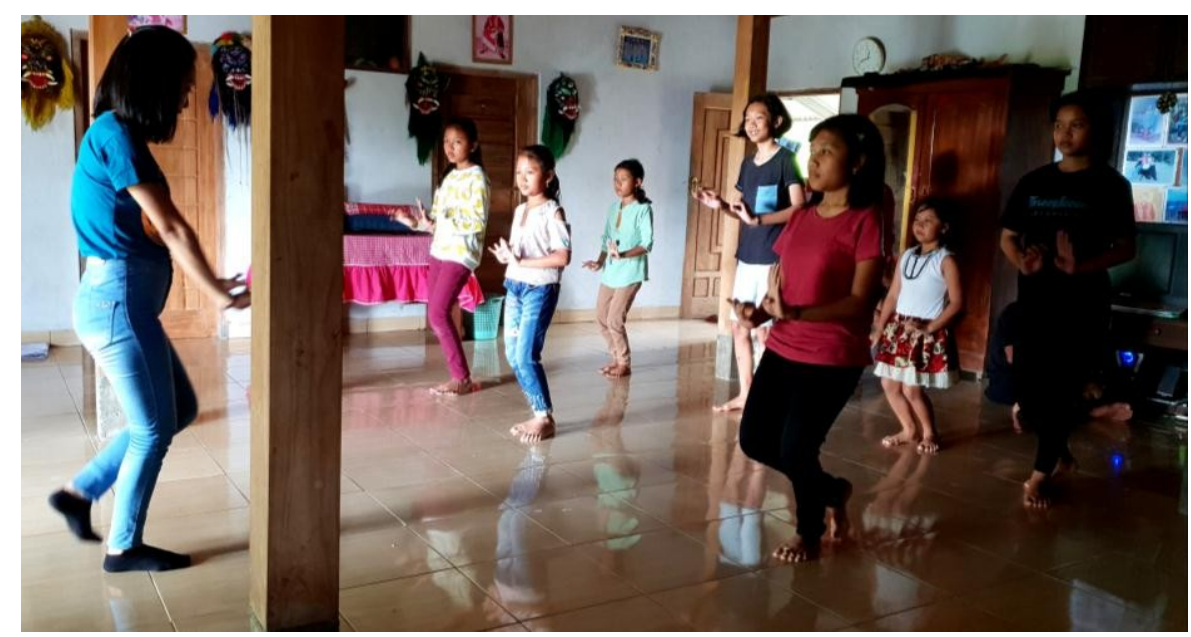

Gambar 1 Pelatihan awal tari Nawung Sekar (Dokumentasi: Hendro, 2019)

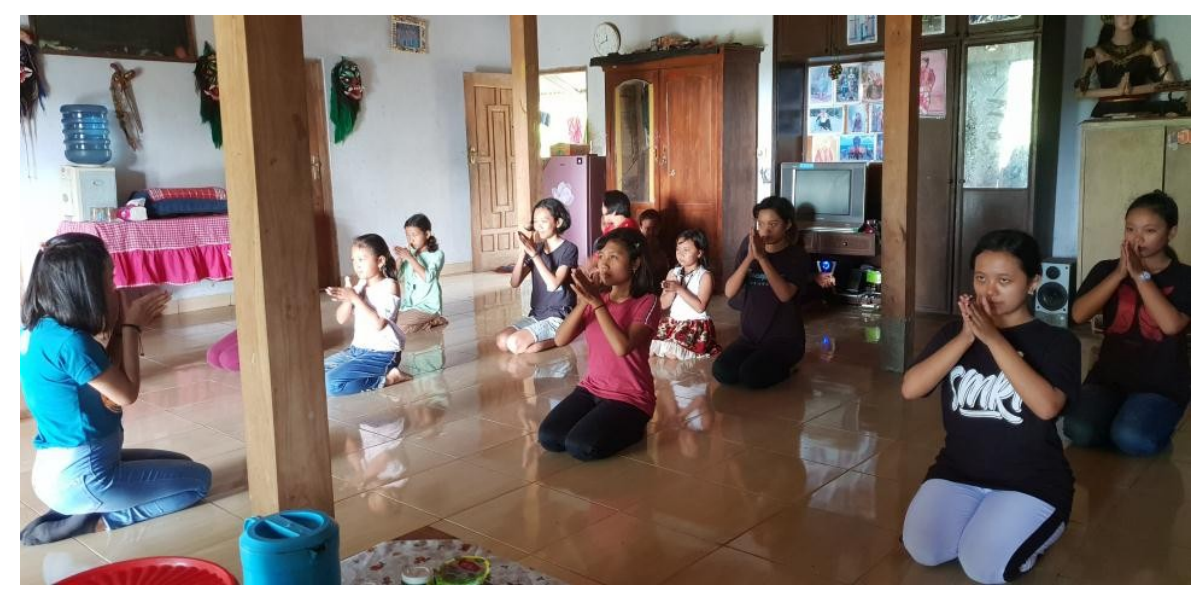

Gambar 2 Motif sembahan

(Dokumentasi: Hendro, 2019)

b. Pertemuan ke-2: 30 Maret 2019, pukul $13.00-16.00 \mathrm{WIB}$

Mengulang tari secara lengkap. Ada beberapa anak SMP yang tidak bisa hadir karena mengikuti study tour sekolahnya, suasana latihan menjadi kurang bersemangat karena hanya diikuti oleh empat anak SD dan SMA.

c. Pertemuan ke-3: 6 April 2019, pukul $13.00-16.00$ WIB
Awanda sang pelatih sedang pentas di tempat lain sehingga digantikan oleh kawannya yang bernama Mega Palawa. Ia juga merupakan mahasiswa Program Studi Tari Semester VI. Kebetulan rumahnya berada di Wonosari yang hanya berjarak sekitar 45 menit dari Kemadang. Jumlah peserta kembali banyak, yakni sembilan orang. Materinya masih mengulang hafalan dan teknik gerak tangan dan kaki. 


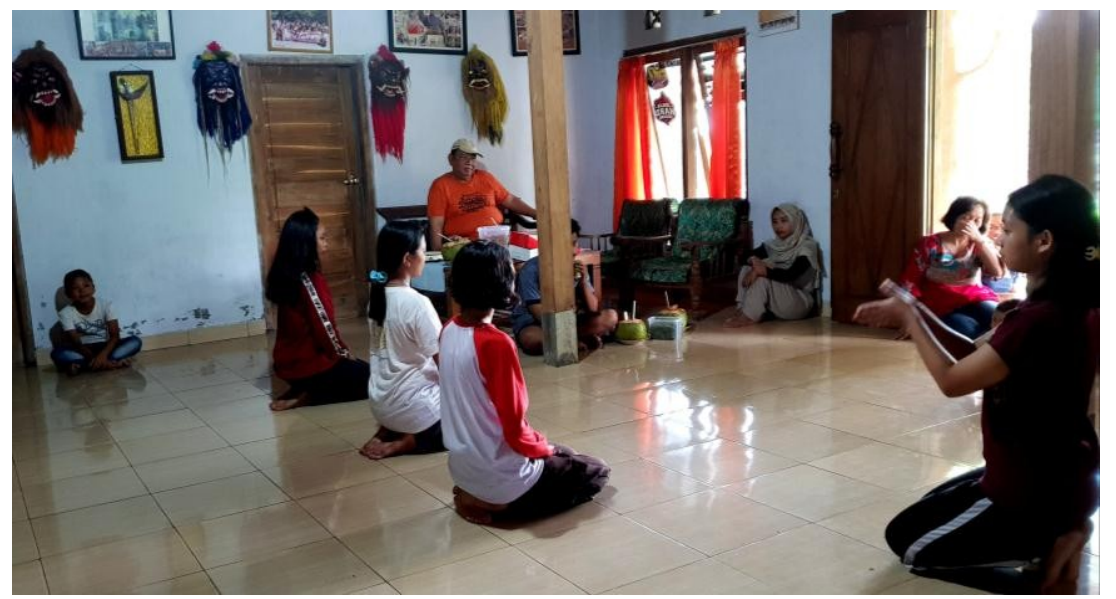

Gambar 3 Pelatihan oleh pelatih pengganti (Dokumentasi: Hendro, 2019)

d. Pertemuan ke-4: 13 April 2019, pukul 13.00 - 16.00 WIB

Kembali Awanda bisa melatih dengan mengulang hingga penari hafal gerak dan urutan tarinya. Latihan ini diselingi kegiatan mencoba desain kostum yang akan digunakan, berupa lilitan kain batik dan stagen yang membungkus tubuh bagian dada penari. Sutinem, istri Sugiyo sang tuan rumah, juga diajari cara penggunaan kostum ini agar nantinya bila akan pentas pada akhir pertemuan bisa memakaikan kostum.

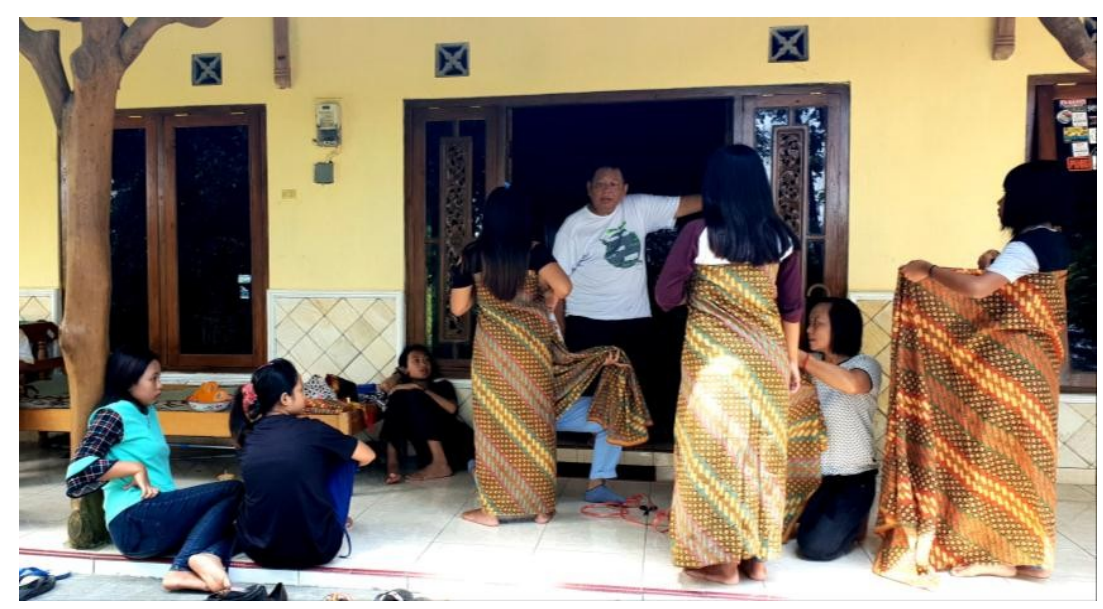

Gambar 4 Pelatihan pemakaian kostum tari Nawung Sekar (Dokumentasi: Hendro, 2019) 


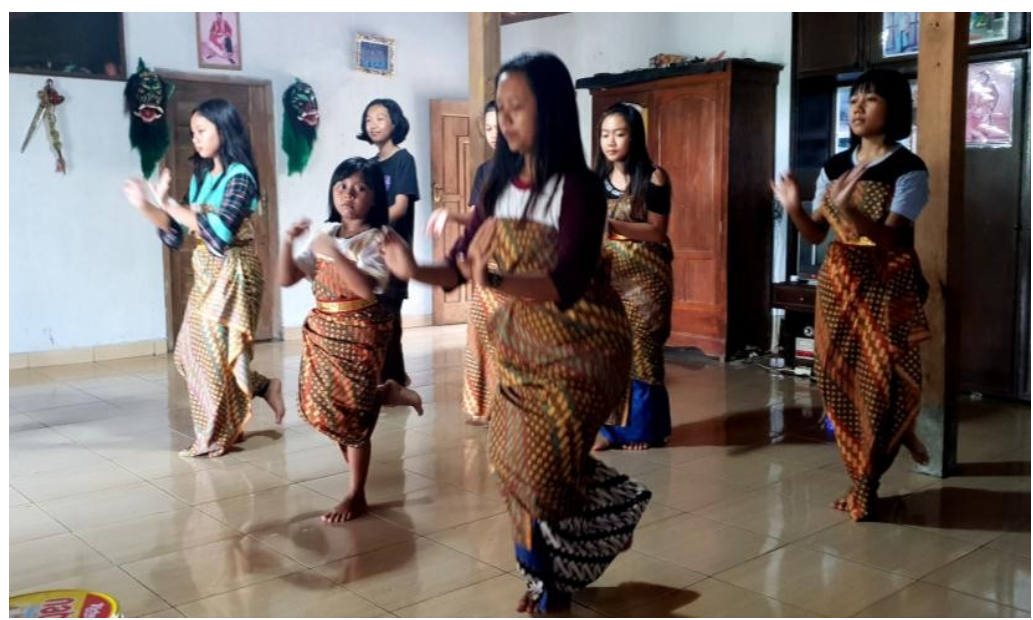

Gambar 5 Latihan dengan mengenakan sebagaian kostum tari Nawung Sekar

(Dokumentasi: Hendro, 2019)

e. Pertemuan ke-5: 20 April 2019, pukul $13.00-16.00 \mathrm{WIB}$

Pertemuan kelima atau latihan kesepuluh, bertempat di Pendhapa Pantai Kukup yang rencananya sekalian digunakan untuk pertemuan terakhir, yaitu pentas. Orientasi tempat yang berbeda membuat anak-anak peserta latihan agak gugup karena tempatnya lebih terbuka dan di keramaian tempat wisata yang dilihat oleh banyak wisatawan walaupun sambil berjalan menuju pantai atau kembali ke tempat parkir. Setelah gerakan diulang beberapa kali dan pola lantai diatur, mereka mulai terbiasa dan tidak gugup lagi. Sabtu, 20 April 2019 ini merupakan latihan terakhir hingga minggu depan harus sudah siap pentas. Sebanyak empat orang hendak mengikuti acara kemah bakti dan ujian sekolah pada Sabtu, 27 April 2019, saat pentas. Maka jam pentas diputuskan diundur dari pukul 11.00 menjadi 14.00 WIB agar mereka bisa ikut pentas.

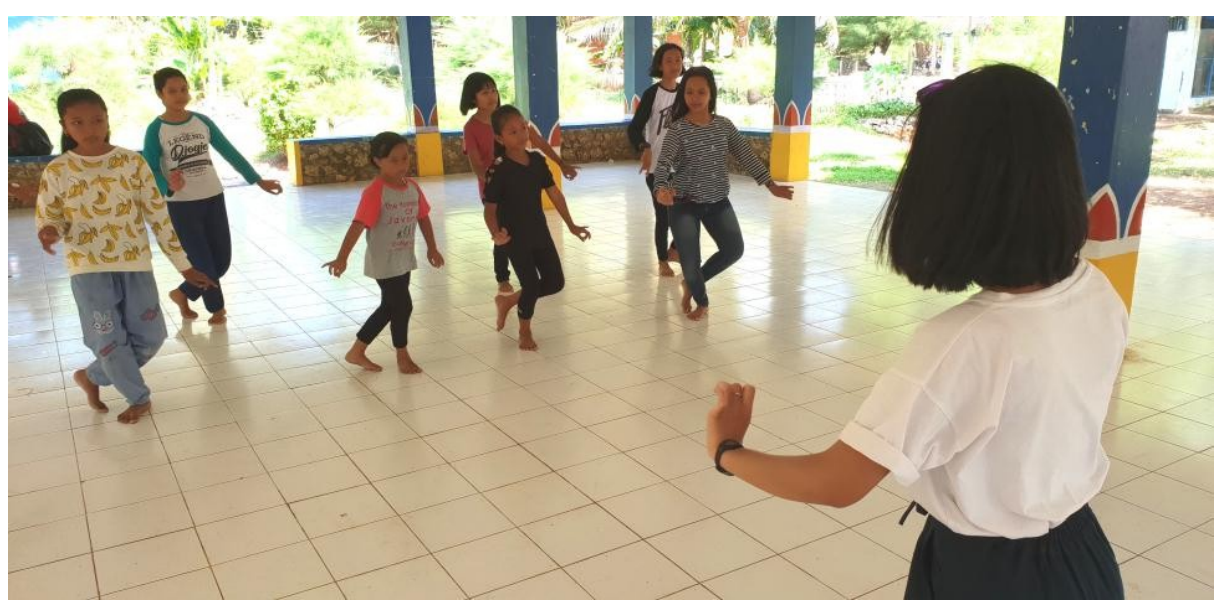

Gambar 6 Latihan di Pendhapa Pantai Kukup

(Dokumentasi: Hendro, 2019)

f. Pertemuan ke-6: 27 April 2019, pukul $13.00-16.00 \mathrm{WIB}$
Merupakan pentas unjuk diri hasil pelatihan selama satu setengah bulan ini. Dirasakan kurang jauh dari kata sempurna 
karena memang latihan tari Jawa gaya Yogyakarta memerlukan latihan bertahuntahun hingga bisa terampil dengan luwes.

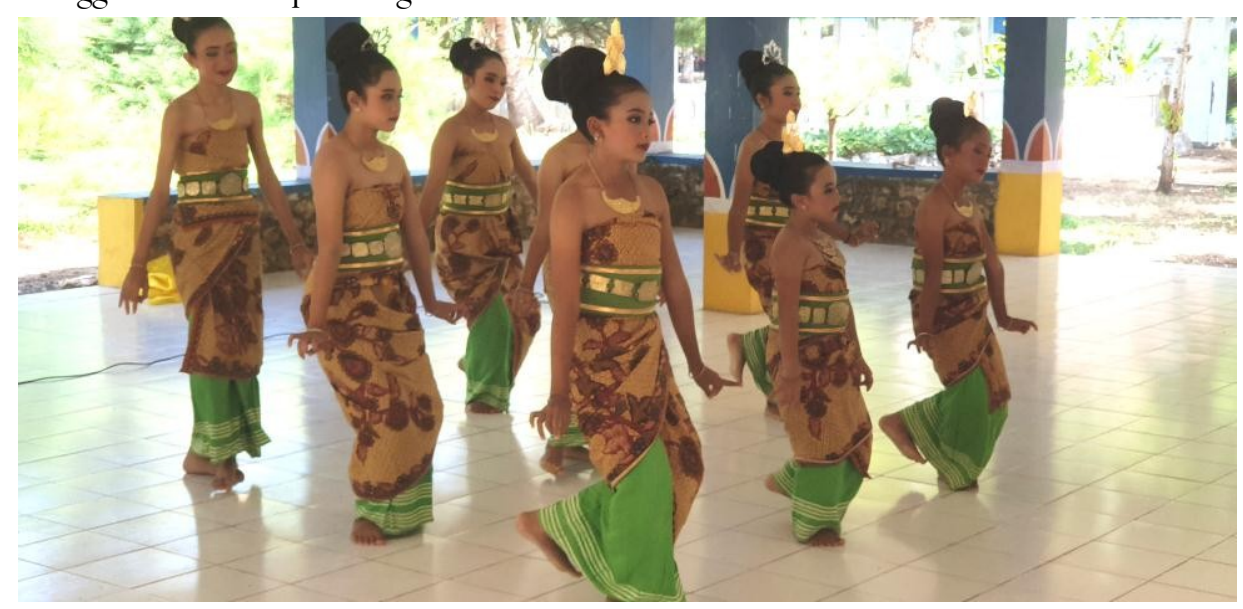

Gambar 7 Pentas di akhir pertemuan di pendhapa pantai Kukup

(Dokumentasi: Hendro, 2019)

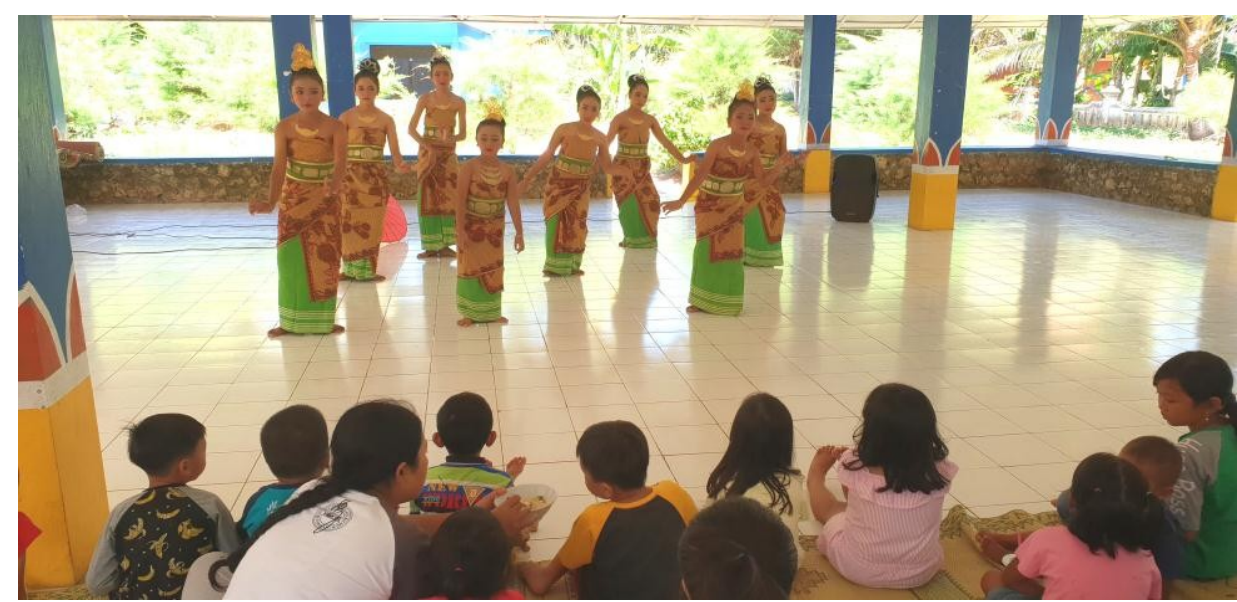

Gambar 8 Pentas ditonton anak-anak pedagang di Pantai Kukup (Dokumentasi: Hendro, 2019)

\section{SIMPULAN}

Tari Yogyakarta memang sulit baik secara teknis maupun hafalan. Mahasiswa program studi tari saja masih kesulitan walau sudah berlatih bertahun-tahun, apalagi anakanak dan remaja Desa Kemadang yang belum pernah mendapat dasar tari Jawa, kecuali satu anak yang menjadi pelajar SMKI Yogyakarta. Memang, tujuan penyuluhan ini bukan untuk menciptakan penari-penari adiluhung, melainkan memberi stimulus untuk berkesenian kembali di desanya, karena sudah beberapa tahun ini Reog Kaloka mati suri sejak tahun 2012. Dengan mengadakan kegiatan latihan tari diharapkan warga desa kembali tergugah untuk menggiatkan kembali berkesenian paling tidak semingga sekali seperti dulu.

Kendala lain adalah waktu luang peserta penyuluhan sangat padat kegiatan sekolah, ibadah gereja, dan membantu orang tua jualan di Pantai Wisata Kukup 
dan Baron. Waktu luang hanya Sabtu siang hingga sore, apalagi satu anak yang berpotensi juga kos di Yogyakarta, hanya Jumat sore atau Sabtu pagi pulang ke desa. Terlebih, Minggu semua orang padat kegiatan tidak bisa diganggu gugat. Jadi, warga desa memiliki kesibukan yang sama dengan masyarakat perkotaan. Tidak ada lagi warga Dusun Kemadang yang santai tidak memiliki pekerjaan. Lapangan kerja berada di pantai wisata yang banyak sekali di daerah tersebut, dari penjaga karcis masuk lokasi, tukang parkir, jualan makanan dan suvenir, jasa fotografi, penjaga kamar mandi, nelayan, dan masih ada bidang pekerjaan nonformal di sektor pariwisata. Dampaknya warga meninggalkan dusunnya dari pagi hingga petang, desa menjadi sepi hanya ada anak anak dan para orang tua renta. Begitu tiba di rumah meraka langsung istirahat hingga besok pagi berangkat lagi ke pantai mengais rezeki. Tidak ada lagi waktu dan energi berkesenian seperti dahulu saat pantai masih sepi pengunjung. Reog dan seni yang lain hanya ada bila menjelang pentas di acara Rasulan. Setelah itu mati suri panjang hingga tahun berikutnya. Kasus ini juga melanda semua dusun sekitar pantai wisata yang memiliki kesenian, sungguh ironis.

Hasil penyuluhan ini berupa kemampuan anak-anak dan remaja putri Kemadang yang bisa menarikan tari Jawa gaya Yogyakarta dalam taraf dasar, walaupun sebagian besar masih perlu latihan lebih intensif, kecuali satu peserta, yakni Debora Kriswandari yang pelajar SMKI Yogyakarta. Ia sudah dapat menguasai teknik karena sudah mendapatkan pelajaran tari di sekolahnya.

\section{SARAN}

Tujuan pelaksana program memang bukan akan mencetak menjadi penari adiluhung, tetapi pengenalan secuil tari klasik Jawa ke masyarakat desa memang harus memerlukan keseriusan yang tinggi dan waktu yang lama. Selama ini warga desa Suru hanya mengenal tari Reog, Jathilan, atau Buto Grasak yang merupakan kesenian yang berasal dari rakyat. Mereka belum mengenal tari Yogyakarta yang berasal dari kraton.

Ada hal yang ditakuti oleh pelaksana penyuluhan, yaitu warga desa tidak terbiasa mengikuti latihan tari dengan rutin, kecuali Reog Kaloka yang dulu memiliki jadwal rutin latihan setiap malam Minggu. Meski demikian, hal itu sudah tidak pernah terlaksana lagi karena kesibukan dan kelelahan para warga setelah seharian mencari nafkah di pantai wisata yang dimulai sejak pagi pukul 09.00 hingga 17.00 WIB setiap harinya. Dahulu bisa terlaksana latihan rutin disebabkan tidak ada kesibukan warga yang menyita waktu dan energi. Mereka hanya bekerja di ladang sehingga bisa mengatur waktu sesuai kehendak hati. Lain halnya bila sedang tanam atau panen, waktu dan tenaga bisa terkuras di ladang. Dalam kasus ini, kehadiran anak dan remaja dalam mengikuti latihan yang di atas 95\% patut diapresiasi. Hanya satu kali yang tidak hadir, yaitu anak SMP, karena ada study tour. Selebihnya bisa hadir terus dan bersemangat mengikuti latihan, hanya tidak bisa latihan di luar Sabtu karena salah satu peserta, yaitu Debora Wanda anak Sugiyo yang sekolah di SMKI Yogyakarta, tidak bisa meneruskan latihan di luar jadwal penyuluhan karena ia indekos di Yogyakarta. Ia hanya pulang ke desa setiap Jumat sore, kadang Sabtu pagi, lalu Senin pagi sudah kembali ke Kota Yogyakarta. Sementara Minggu digunakan untuk beribadah ke gereja, juga ada kesibukan lain yang menyebabkan tidak bisa latihan.

Namun, pengenalan ini paling tidak membuka wawasan para remaja untuk berlatih tari yang lebih serius dengan studi di sekolah tari hingga perguruan tinggi seni. Efek domino yang diharapkan adalah kelak bila tiba 
masanya para remaja bisa membangun kesenian terutama tari dengan mengembangkan seni rakyat yang berada di desa tempat tinggalnya. Membawa ke tingkat yang lebih tinggi bahkan ke kancah internasional, seperti yang dilakukan oleh Reog Ponorogo, Ratoh atau Saman Aceh, tari Minang, dan tari Bali. Para seniman daerah tersebut bangkit dari desanya berbekal potensi lokal, tetapi berpikir secara internasional jauh ke depan.

Salah satu tujuan penyuluhan ini adalah menghidupkan kembali kegiatan berkesenian dimulai dengan latihan tari untuk anak-anak yang kelak memegang tanggung jawab atas keberadaan seni rakyatnya. Semoga harapan ini dapat tercapai walaupun jalan masih panjang, terjal, dan berliku seperti jalan menuju desa ini.

\section{UCAPAN TERIMA KASIH}

Terima kasih dihaturkan kepada Ketua LPM ISI Yogyakarta, Dr. Nursahid, M.Hum. atas kesempatan yang diberikan untuk melaksanakan program penyuluhan seni ini. Terima kasih dihaturkan pula kepada Paguyuban Reog Kaloka atas kerja samanya sehingga program ini dapat berjalan dengan baik.

\section{DAFTAR PUSTAKA}

Sulastuti, Katarina Indah. (2013). "FaktorFaktor yang Mempengaruhi Kualitas Rasa dalam

Tari Jawa Gaya Surakarta." Gelar: Jurnal Seni Budaya, Volume 11, Nomor 1.
Ifdil, I., Denich, A. U., \& Ilyas, A. (2017). "Hubungan Body Image dengan Kepercayaan

Diri Remaja Putri.” Jurnal Kajian Bimbingan dan Konseling, Volume 2, Nomor 3, pp. 107-113.

Isnanda, Romo. \& Azkiya, Hidayat. (2019).

"Fungsi Kesenian Rakyat dalam Penataan Sanggar sebagai Upaya Menjaga

Eksistensi Budaya Lokal. Bahastra: Jurnal

Pendidikan Bahasa dan Sastra Indonesia,

Volume 3, Nomor 2, Maret.

Kismini, Elly. (2013). "Eksistensi Budaya Seni Tari Jawa di Tengah Perkembangan

Masyarakat Kota Semarang. FIS:

Forum Ilmu Sosial, Volume 40, Nomor 1, Juni 